\title{
Psychological Determinants and Consequences of COVID-19 Anxiety: A Web-Based Study in Iran
}

\author{
Reza Shabahang ${ }^{1} \odot$, Mara S. Aruguete ${ }^{2} \odot$, Sajjad Rezaei ${ }^{3} \odot$, Lynn E. McCutcheon ${ }^{4} \odot$ \\ ${ }^{1}$ Department of Psychology, University of Tehran, ${ }^{2}$ Lincoln University, ${ }^{3}$ University of Guilan, ${ }^{4}$ North American Journal of Psychology \\ Keywords: panic buying, depression, interpersonal trust, uncertainty intolerance, health anxiety, covid-19 \\ https://doi.org/10.52965/001c.24841
}

Health Psychology Research

Vol. 9, Issue 1, 2021

\begin{abstract}
Pandemic illnesses such as COVID-19 can provoke negative emotions, including anxiety and depression, in addition to compulsive behaviors. Clarifying the psychosocial antecedents and consequences of COVID-19 anxiety can inform successful psychological support and treatment. This study investigated psychological predictors and consequences of COVID-19 anxiety during the outbreak of COVID-19 in Iran. University students $(\mathrm{N}=398)$ completed a web-based survey measuring COVID-19 anxiety, general health anxiety, uncertainty intolerance, interpersonal trust, depression, and COVID-19-related panic shopping. The participants also responded to two additional questions: "Do you personally know of anyone who was suspected of having been infected with COVID-19?" and "Did you get sick in the past year?” Exploratory factor analysis, confirmatory factor analysis, Pearson correlation, multiple regression analysis, multivariate regression analysis, and $2 \times 2$ factorial ANOVA were used to analyze data. Health anxiety, uncertainty intolerance, and interpersonal trust were significantly associated with COVID-19 anxiety. COVID-19 anxiety was a significant predictor of depression and panic shopping. Participants who knew someone with COVID-19 and those who reported being sick in the past year experienced more COVID-19 anxiety. COVID-19 anxiety appears to be more severe among people with a low tolerance for uncertainty and low interpersonal trust. Understanding these risk factors can inform individualized therapeutic approaches to address the maladaptive outcomes of depression and false safety behaviors, such as panic buying.
\end{abstract}

\section{INTRODUCTION}

COVID-19 spread rapidly across the globe, resulting in unprecedented quarantine measures and social isolation. In addition to creating a public health crisis, the pandemic has produced serious psychological consequences in the global population. ${ }^{1}$ A worldwide wave of uncertainty about the consequences of the virus occurred. ${ }^{2}$ Economic impacts and lifestyle changes, such as school closures, were associated with increased anxiety. ${ }^{3}$ A meta-analysis of 17 studies on the mental health impacts of COVID-19 in a range of different countries showed that about one-third of the general population was affected by increased stress, anxiety, and depression. ${ }^{1}$ For example, in a large-scale Chinese study on the perceived impact of COVID-19 in a community sample, over half of participants rated the personal psychological implications of the virus as moderate to severe. ${ }^{4}$ Anxiety and depression were common, and preexisting characteristics (such as poor health status) predicted a more significant psychological impact. ${ }^{4}$ Likewise, a study of over 17,000 social media users showed an increase in posts displaying negative emotions and a decrease in posts displaying positive emotions since the COVID-19 outbreak was initially revealed. ${ }^{5}$ Therefore, the prevailing research on COVID-19 shows that the pandemic resulted in negative psychological impacts on communities across the globe.

Research into the mental health impacts of COVID-19 is urgently needed to develop appropriate support and treatment. Understanding the factors that make some individuals more vulnerable to adverse psychological effects of the pandemic will help to target appropriate mental health interventions. The present study investigates the factors associated with anxiety related to COVID-19. Specifically, we examine depression, health anxiety, uncertainty intolerance, panic shopping, interpersonal trust, and stressful life events.

\section{HEALTH ANXIETY}

Health anxiety refers to perceiving even benign bodily changes as signs of a severe illness. ${ }^{6}$ Health anxiety has increased since the outbreak of COVID-19 and is associated with a range of maladaptive behaviors, such as over-seeking or under-seeking medical treatment. ${ }^{7}$ Individuals with high health anxiety exhibit a range of maladaptive illness cognitions, ${ }^{8}$ including negative affect and rumination. ${ }^{9-11}$ Individuals with health anxiety may be particularly vulnerable to COVID-19 anxiety. 


\section{UNCERTAINTY INTOLERANCE}

Uncertainty, or fear of the unknown, is tightly associated with anxiety ${ }^{12}$ and is central to the COVID-19 pandemic. $^{13}$ High uncertainty is a distressful condition that people are generally motivated to avoid. Uncertainty intolerance ${ }^{14} \mathrm{de}-$ scribes the continuum of adverse reactions to uncertainty. Uncertainty intolerance leads some people to experience significant distress over indeterminate conditions. This can result in maladaptive behaviors such as being inhibited from an action or exhibiting problematic behaviors to reduce uncertainty and increase perceived control. ${ }^{15}$ Health anxiety is positively associated with uncertainty intolerance. ${ }^{14}$ Uncertainty intolerance may be particularly susceptible to COVID-19 anxiety since uncertainty plays a significant role in the pandemic. At a basic level, people are uncertain about whether or not they or their loved ones will contract the virus. If they contract the virus, the health consequences are difficult to predict and can range from mild symptoms to death. Beyond these primary fears, the list of uncertainties is exhaustive (e.g., How long will the pandemic last? Will there be a vaccine?). Given the ambiguity of so many important life conditions during a pandemic, it is reasonable to assume that perceived uncertainty will tend to be high. Those with high uncertainty intolerance will be at risk for more significant negative affect.

\section{PANIC SHOPPING}

In addition to causing adverse effects, uncertain situations may motivate people to reduce uncertainty by engaging in problematic behaviors that make them feel safe. One of these behaviors is panic shopping. ${ }^{16}$ For example, during the COVID-19 pandemic, consumers have been motivated to empty grocery store shelves of perceived necessities like bread, milk, and eggs. Stockpiling daily necessities allows people to reduce uncertainty about the availability of necessary goods in the future. In short, stockpiling will enable people to exert some control over an unpredictable situation. While these "safety behaviors" may make people feel better in the short term, there are negative long-term consequences, including strain on consumers' finances, increased risk of exposure to the virus, increased risk of community transmission of the virus, risk of exposure for vulnerable populations who may be present in stores, and over-buying resulting in waste.

\section{INTERPERSONAL TRUST}

One factor that might decrease uncertainty and anxiety is interpersonal trust. People who exhibit high interpersonal trust feel they can count on others to be responsive to their needs. ${ }^{17}$ Therefore, those high in interpersonal trust are more relaxed and secure. In addition, interpersonal trust is associated with better physical health, and this relationship is mediated by reductions in anxiety and depression. 18 Since the tendency to trust others extends to healthcare workers and government officials, one can quickly see how interpersonal trust might mitigate stressful reactions to the COVID-19 pandemic.

\section{STRESSFUL LIFE EVENTS}

Stressful life events may also prime COVID-19 anxiety. Those with preexisting health problems may experience more significant anxiety due to increased feelings of vulnerability to the disease. ${ }^{4}$ In addition, people who know others suspected to have been infected with COVID-19 may feel greater vulnerability. Higher expectations about exposure to disease are likely to amplify the pandemic's adverse mental and physical health reactions. ${ }^{8}$

\section{THE PRESENT STUDY}

This paper explores COVID-19 anxiety to document the possible risk factors and consequences of severe mental health reactions. We used a quantitative, web-based survey to examine COVID-19 anxiety, depression, general health anxiety, uncertainty intolerance, interpersonal trust, and panic-shopping in a sample of university students in Iran. Our hypotheses are as follows: (1) COVID-19 anxiety will be associated with depression, general health anxiety, and panic shopping, (2) COVID-19 anxiety will be more significant among participants with the risk factors of high uncertainty intolerance and low interpersonal trust, and (3) Participants who have recently experienced illness or who know someone suspected of having COVID-19 will experience more significant COVID-19 anxiety.

\section{METHOD}

In this online survey research, we sought to investigate psychological predictors and consequences of COVID-19 anxiety during the outbreak of COVID-19 in Iran. Initially, we developed and validated a brief one-dimensional questionnaire to measure COVID-19-Related Panic Shopping. Then, we tested the hypotheses concerning the psychological determinants and consequences of COVID-19 anxiety.

\section{STUDY SETTING AND PARTICIPANTS}

Our study participants were students of Guilan University in Rasht, Iran. In this web-based study, participants were recruited using an online advertisement posted on a university student social network. The link to the online survey was sent directly to students who were members of university-related groups on social media. Google Forms was used to collect data to minimize risks of COVID-19 transmission among participants and researchers. To ensure that data were gathered from the intended population, each participant was asked to enter their academic email or student number. The response rate was $44 \%$. The participants were 204 male and 194 female university students between the ages of 18 - 45 years $(M=26.58, S D=6.16)$. Our inclusion criteria were: (a) age between 18 and 45 years; and (b) written consent. The exclusion criteria consisted of: (a) self-report of severe psychological or physical disability; (b) receiving active psychological or physical treatment; (c) frequent alcohol/drug use; and (d) incomplete responding. A sample of 403 participants was initially recruited, but five were excluded due to our criteria. The remaining 398 responses were analyzed. 


\section{PROCEDURE}

Participants received an Internet-based survey administered in Persian. The survey consisted of COVID-19 anxiety, general health anxiety, uncertainty intolerance, interpersonal trust, depression, and COVID-19-related panic shopping. Participants also responded to two additional questions: "Do you personally know of anyone who was suspected of having been infected with COVID-19?" and "Did you get sick in the past year?"

For evaluating psychometric properties of the COVID-19-Related Panic Shopping Questionnaire, exploratory factor analysis, confirmatory factor analysis, and Cronbach's alpha were used. Fabrigar, Wegener, MacCallum, and Strahan ${ }^{19}$ suggested conducting EFA and CFA on different datasets to increase reliability. In this study, EFA ( $n=200)$ and CFA $(n=198)$ were conducted using subsamples derived from the total sample $(N=398)$. According to the recommended sample sizes for factor analysis by Comrey and Lee, ${ }^{20} 200$ graded as fair, our EFA and CFA sample sizes are considered adequate.

After evaluating the psychometric properties of the COVID-19-Related Panic Shopping Questionnaire, Pearson correlation, multiple regression analysis, multivariate regression analysis, and $2 \times 2$ factorial design ANOVA were used on a total of 398 responses to investigate hypotheses related to psychological determinants and consequences of COVID-19 anxiety.

\section{INSTRUMENTS}

COVID-19 Anxiety Questionnaire: For assessing COVID-19 pandemic anxiety, we adapted items from the Swine Flu Inventory. ${ }^{21}$ The resulting COVID-19 Anxiety Questionnaire consisted of 10 items that covered concerns about the spread of COVID-19 (e.g., "to what extent do you believe that COVID-19 could become a pandemic in Iran?"); the perceived likelihood of contracting the disease (e.g., "how likely is it that you could become infected with COVID-19?"); perceived severity of the disease (e.g., "if you did become infected with COVID-19, to what extent are you concerned that you will be severely ill?"); and exposure to information about the disease (e.g., "how much exposure have you had to information about COVID-19?”). The COVID-19 Anxiety Questionnaire is scored on a five-point Likert scale ranging from not at all (1) to very much (5). Higher scores are indicative of more significant COVID-19 anxiety. The content validity, convergent validity, and reliability of the CVAQ have been established. ${ }^{22,23}$ Shabahang, Aruguete, \& McCutcheon ${ }^{23}$ reported good convergent validity of the questionnaire by examining the correlation between the COVID-19 Anxiety Questionnaire and Short Health Anxiety Inventory $(r=0.62 ; p<0.01)$. Nourisaeid et al. ${ }^{24}$ additionally confirm the content validity and reliability ( $\alpha=.79$ ) of the COVID-19 Anxiety Questionnaire. The current study reports a .81 reliability coefficient using Cronbach's alpha.

Short Health Anxiety Inventory: The Short Health Anxiety Inventory (SHAI) ${ }^{25}$ was used to examine general health anxiety. The survey assesses exaggerated estimates of the likelihood and severity of having an illness with 18 items (e.g., "noticing aches and pains," "chance of medical cure if one has an illness," and "relieved if a doctor says nothing's wrong"). The 18-item SHAI is a shorter version of the 64-item Health Anxiety Inventory (HAI), which has comparable psychometric properties. Each question in the SHAI consists of four statements representing a continuum of health anxiety scored from 0 to 3 , with higher values indicating more significant health anxiety. The maximum score on the scale is 54 . Salkovskis et al. ${ }^{25}$ reported satisfactory reliability, validity, and sensitivity to treatment of the SHAI. The SHAI has demonstrated excellent validity and reliability in previous studies across samples. ${ }^{26,27}$ The Cronbach's alpha coefficients ranged from .74 to .96 in previous studies. ${ }^{27}$ In the present study, Cronbach's alpha coefficient was .82 .

Intolerance of Uncertainty Scale-12 Item: The Intolerance of Uncertainty Scale-12 Item (IUS-12) ${ }^{15}$ is a short version of the original Intolerance of Uncertainty-27 item Scale (IUS-27) ${ }^{28}$ that measures the degree to which uncertainty in life is stressful and unsettling. The IUS-12 has similar psychometric properties as the IUS-27. ${ }^{29}$ The IUS-12 consists of two factors including prospective anxiety (7 items; e.g., "Unforeseen events upset me greatly" and "A small, unforeseen event can spoil everything, even with the best of planning") and inhibitory anxiety (5 items; e.g., "Uncertainty keeps me from living a full life" and "The smallest doubt can stop me from acting"). The response options ranged from 1 (not at all characteristic of me) to 5 (entirely characteristic of $m e$ ). The scale has satisfactory validity and reliability. ${ }^{15}$ Carleton et al. ${ }^{15}$ reported excellent reliability for all 12 items $(\alpha=.91)$, the prospective anxiety subscale ( $\alpha=$ $.85)$, and the inhibitory anxiety subscale $(\alpha=.85)$. The alpha reliability was .76 and .78 for prospective anxiety and inhibitory anxiety in the present sample, respectively.

Interpersonal Trust Scale: The Interpersonal Trust Scale (ITS) was developed by Rotter ${ }^{17}$ to measure the generalized expectancy that another individual or group can rely upon. The ITS has 25 items (e.g., "Hypocrisy is on the increase in our society," "This country has a dark future unless we can attract better people into politics," "It is safe to believe that despite what people say, most people are primarily interested in their own welfare," and "In these competitive times one has to be alert or someone is likely to take advantage of you"). It is scored on a 5-point Likert scale, with strongly agree equal to 1 and strongly disagree equal to 5 . The range of scores is $25-125$, with higher scores indicating higher interpersonal trust. The validity and reliability of the ITS have been established. ${ }^{17,30}$ Good internal consistency based on split-half reliability $(r=.76, p<.001)$ was reported by Rotter. ${ }^{17}$ The Cronbach's alpha for the present sample was .80 .

Beck Depression Inventory-Second Edition: The Beck Depression Inventory-Second Edition (BDI-II) contains 21 items that measure critical aspects of depression, including a sense of failure, guilt, self-dissatisfaction, social withdrawal, and loss of libido. ${ }^{31}$ The BDI-II is a self-report screening instrument with each item rated with a set of four possible answer choices of increasing intensity $(0=$ least, 3 $=$ most $)$. The items are summed to create a total score with a range of $0-63$. Beck, Steer, and Brown ${ }^{32}$ defined four categories based on total raw score ranges: Minimal (0-13), Mild (14-19), Moderate (20-28), and Severe (29-63). Satis- 


\begin{tabular}{|c|c|c|c|c|}
\hline Item & Factor 1 & $h^{2}$ & Mean & SD \\
\hline $\begin{array}{l}\text { 1. I immediately buy a product / service if I believe it is useful for overcoming } \\
\text { COVID-19. }\end{array}$ & .71 & .51 & 3.36 & 1.15 \\
\hline $\begin{array}{l}\text { 2. I am out of control in purchasing products/services such as masks, sanitary gloves, } \\
\text { and hand sanitizer for coping with COVID-19. }\end{array}$ & .79 & .63 & 2.03 & 1.27 \\
\hline $\begin{array}{l}\text { 3. I purchase more masks, sanitary gloves, hand sanitizers, and food than I previously } \\
\text { planned. }\end{array}$ & .78 & .64 & 2.16 & 1.12 \\
\hline $\begin{array}{l}\text { 4. I feel a compulsion to buy products/services such as masks, sanitary gloves, and } \\
\text { hand sanitizer to cope with COVID-19. }\end{array}$ & .80 & .63 & 2.88 & 1.19 \\
\hline $\begin{array}{l}\text { 5. Buying lots of masks, sanitary gloves, hand sanitizers, and food makes me feel } \\
\text { secure. }\end{array}$ & .82 & .68 & 2.76 & 1.22 \\
\hline
\end{tabular}

factory psychometric properties of the BDI-II have been established. ${ }^{32}$ Numerous studies provide evidence for reliability and validity across different populations and cultural groups. ${ }^{33,34}$ Previous studies on the BDI-II reported Cronbach's alpha coefficients ranging from .83 to $.96 .{ }^{35} \mathrm{BDI}-\mathrm{II}$ items showed high internal consistency in the present sample $(\alpha=.83)$.

COVID-19-Related Panic Shopping Questionnaire: The COVID-19-Related Panic Shopping Questionnaire was constructed for the present study to measure shopping behavior associated with COVID-19. Five items were adapted by considering the Buying Impulse Scale ${ }^{36}$ and the Impulse Buying Tendency Scale. ${ }^{37,38}$ The 5 adapted items measure unintended, immediate, and unreflective purchases regarding the COVID-19 outbreak (e.g., "I immediately buy a product/service if I believe it is useful for overcoming COVID-19" and "I feel a compulsion to buy products/services such as masks, sanitary gloves, and hand sanitizer to cope with COVID-19”). The psychometric properties of the COVID-19-Related Panic Shopping Questionnaire are evaluated in the present study using exploratory factor analysis (EFA), confirmatory factor analysis (CFA), and Cronbach's alpha.

The participants also were asked to respond to the following questions: "Do you personally know of anyone who was suspected of having been infected with COVID-19?" and "Did you get sick in the past year?" Participants answered these questions with yes-or-no response options.

\section{DATA ANALYSIS}

The data were analyzed using SPSS 24 and Amos statistical software packages. Exploratory factor analysis, confirmatory factor analysis, Pearson correlation, multiple regression analysis, multivariate regression analysis, and $2 \times 2$ factorial design ANOVA were applied to examine the Panic Shopping Questionnaire's psychometric properties and test research questions.

\section{RESULTS}

PSYCHOMETRIC PROPERTIES OF THE COVID-19-RELATED PANIC SHOPPING QUESTIONNAIRE

Before hypothesis testing, we sought to establish the psychometric properties of the COVID-19-Related Panic Shopping Questionnaire using Cronbach's alpha, exploratory factor analysis, and confirmatory factor analysis. The mean score on the COVID-19-Related Panic Shopping Questionnaire score was $14.01(S D=4.50)$. Based on the criterion of .30 recommended by Nunnally and Bernstein, ${ }^{39}$ each item indicates satisfactory item-total correlation (Range $=.40$ .76). Positive and significant correlation coefficients suggest that the questionnaire generally measures a unitary construct. The Cronbach's alpha internal reliability was .78.

Exploratory Factor Analysis (EFA) was used to investigate the factor structure of the COVID-19-Related Panic Shopping Questionnaire $(n=200)$. Two hundred of 398 responses were analyzed with EFA. The KMO index was .84 and Bartlett's test for sphericity was significant $(\chi 2=$ 379.16; $d f=10 ; p<.0001$ ), indicating suitability of data for structure detection. The EFA of 5 items yielded a one-factor model that accounted for $61.75 \%$ of the variance.

The confirmatory factor analysis (CFA) was performed to test the one-factor model of the COVID-19-Related Panic Shopping Questionnaire $(n=198)$. The remaining subsample of 198 (of 398 total) responses were analyzed with CFA.

The model fit indices were as follows: Relative chisquare, goodness-of-fit index (GFI), adjusted goodness of fit index (AGFI), normed fit index (NFI), Tucker-Lewis index (TLI), comparative fit index (CFI), and root mean square error of approximation (RMSEA). ${ }^{40}$ Considering the recommended cut-offs for a good fit, the one-dimensional model indicated an acceptable fit across most indices (Table 2).

\section{PSYCHOLOGICAL DETERMINANTS AND CONSEQUENCES OF COVID-19 ANXIETY}

Table 3 examines the suitability of data for hypothesis testing by presenting ranges, mean scores, standard deviations, skewness, kurtosis, and Cronbach's alpha for each measure. According to skewness and kurtosis values, the variables follow a normal distribution in our population. ${ }^{41}$ Internal 
Table 2. Goodness-of-fit indices for the one-factor model of the COVID-19 Related Panic Shopping Questionnaire $(\mathbf{n}=198)$

\begin{tabular}{|c|c|}
\hline Modification indices & Tested model \\
\hline$x^{2}$ & 13.32 \\
\hline df & 5 \\
\hline $\mathrm{p}$-value & .02 \\
\hline$x 2 / d f$ & 2.66 \\
\hline Goodness of Fit Index (GFI) & .92 \\
\hline Adjusted Goodness of Fit Index (AGFI) & .87 \\
\hline Normed Fit Index (NFI) & .92 \\
\hline Tucker-Lewis Index (TLI) & .85 \\
\hline Comparative Fit Index (CFI) & .95 \\
\hline Root Mean Square Error Of Approximation (RMSEA) & .09 \\
\hline
\end{tabular}

Table 3. Descriptive statics of study's variables $(n=398)$

\begin{tabular}{|c|c|c|c|c|c|c|}
\hline & Min-Max & $M$ & SD & Skewness & Kurtosis & $\alpha$ \\
\hline Health anxiety & $0-33$ & 16.18 & 6.66 & .31 & -.08 & .82 \\
\hline Prospective anxiety & $10-34$ & 22.05 & 5.31 & .20 & -.41 & .76 \\
\hline Inhibitory anxiety & $5-25$ & 14.98 & 4.25 & .03 & -.38 & .78 \\
\hline Interpersonal trust & $33-105$ & 60.34 & 10.34 & .21 & .36 & .80 \\
\hline Depression & $10-45$ & 25.19 & 8.15 & .64 & -.71 & .83 \\
\hline COVID-19 related panic shopping & $5-25$ & 14.01 & 4.50 & .23 & -.51 & .78 \\
\hline COVID-19 anxiety & $10-34$ & 22.05 & 5.31 & .20 & -.41 & .81 \\
\hline
\end{tabular}

Table 4. Correlation matrix of study's variables

\begin{tabular}{|c|c|c|c|c|c|c|c|}
\hline & 1 & 2 & 3 & 4 & 5 & 6 & 7 \\
\hline 1. Health anxiety & 1 & & & & & & \\
\hline 2.Prospective anxiety & $.47^{* *}$ & 1 & & & & & \\
\hline 3.Inhibitory anxiety & $.39^{* *}$ & $.67^{* *}$ & 1 & & & & \\
\hline 4.Interpersonal trust & $-.20^{* *}$ & $.31^{* *}$ & $-.25^{* *}$ & 1 & & & \\
\hline 5.Depression & $.16^{* *}$ & $.18^{* *}$ & $.17^{* *}$ & $-.19^{* *}$ & 1 & & \\
\hline 6.COVID-19 related panic shopping & $.26^{* *}$ & $.33^{* *}$ & $.30^{* *}$ & -.06 & .09 & 1 & \\
\hline 7.COVID-19 anxiety & $.28^{* *}$ & $.39^{* *}$ & $.32^{* *}$ & $-.34^{* *}$ & $.43^{* *}$ & $.15^{* *}$ & 1 \\
\hline
\end{tabular}

${ }^{*} p<.05 . * * 0.01$.

consistency estimates for all variables were satisfactory.

Our first two hypotheses predicted that COVID-19 anxiety would be associated with depression, general health anxiety, panic shopping, uncertainty intolerance, and interpersonal trust. We used Pearson correlations to test these hypotheses. In support of these hypotheses, Table 4 shows that COVID-19 anxiety is significantly correlated with depression $(r=.43 ; p<.01)$, general health anxiety $(r=.28 ; p$
$<.01)$, panic shopping $(r=.15 ; p<.01)$, uncertainty intolerance - prospective anxiety $(r=.39 ; p<.01)$, uncertainty intolerance - inhibitory anxiety $(r=.32 ; p<.01)$, and interpersonal trust $(r=-.34 ; p<.01)$.

A multiple regression analysis was computed to predict COVID-19 anxiety. Health anxiety, uncertainty intolerance - prospective anxiety, uncertainty intolerance - inhibitory anxiety, and interpersonal trust were entered as predictors. 
Table 5. Summary statistics for the regression equation predicting COVID-19 anxiety

\begin{tabular}{|c|c|c|c|c|c|c|c|}
\hline Predictive Variables & $\mathrm{R}^{2}$ & $\Delta \mathrm{R} 2$ & B & Standard Error & $\beta$ & $\mathrm{t}$ & $p$ \\
\hline Final model & .22 & .21 & & & & & \\
\hline Health Anxiety & & & .10 & .05 & .11 & 2.09 & .04 \\
\hline Prospective Anxiety & & & .25 & .07 & .22 & 3.39 & .01 \\
\hline Inhibitory Anxiety & & & .11 & .09 & .08 & 1.29 & .20 \\
\hline Interpersonal Trust & & & -.14 & .03 & -.23 & -4.95 & .00 \\
\hline
\end{tabular}

Table 6. The results of $2 \times 2$ factorial design ANOVA

\begin{tabular}{|c|c|c|c|c|c|c|}
\hline Source & $\begin{array}{l}\text { Dependent } \\
\text { Variables }\end{array}$ & $\begin{array}{l}\text { Mean } \\
\text { Square }\end{array}$ & df & $\mathrm{F}$ & P-value & $\begin{array}{l}\text { Partial } \\
\text { Eta } \\
\text { Square }\end{array}$ \\
\hline Getting sick past year & $\begin{array}{l}\text { COVID-19 } \\
\text { anxiety }\end{array}$ & 598.03 & 1 & 18.93 & .0001 & .05 \\
\hline $\begin{array}{l}\text { Knowing someone who was suspected to have } \\
\text { been infected with COVID-19 }\end{array}$ & $\begin{array}{l}\text { COVID-19 } \\
\text { anxiety }\end{array}$ & 1754.69 & 1 & 55.56 & .0001 & .12 \\
\hline $\begin{array}{l}\text { Getting sick past year } \times \text { Knowing someone } \\
\text { suspected to have been infected with COVID-19 }\end{array}$ & $\begin{array}{l}\text { COVID-19 } \\
\text { anxiety }\end{array}$ & 441.97 & 1 & 13.99 & .0001 & .03 \\
\hline
\end{tabular}

According to the variance inflation factor (VIF) values, the data met the assumption of collinearity (Health anxiety, VIF $=.1 .30$, Tolerance $=.769$; Prospective anxiety, $\mathrm{VIF}=2.05$, Tolerance $=.489 ;$ Inhibitory anxiety, $\mathrm{VIF}=1.83$, Tolerance $=$ .55 ; Interpersonal trust, VIF $=1.11$, Tolerance $=.90$ ). Values of VIF that exceed 10 are often regarded as indicating multicollinearity. ${ }^{42}$ Table 5 shows that the sum of the predictor variables accounted for .22 of the variance in COVID-19 anxiety, and the model was significant $\left(R^{2}=.22, p<.0001\right)$. Health anxiety $(\beta=.11 ; p<.04)$, uncertainty intolerance - prospective anxiety $(\beta=.22 ; p<.01)$, and interpersonal trust $(\beta=-.23 ; p<.001)$ significantly predicted COVID-19 anxiety. Uncertainty intolerance - inhibitory anxiety $(\beta=$ $.08 ; p=.20$ ) was not a significant predictor of COVID-19 anxiety.

Multivariate regression analysis was used to predict depression and COVID-19-related panic shopping through COVID-19 anxiety. The model included COVID-19 anxiety as independent variable (predictor) and depression and COVID-19-related panic shopping as dependent variables (responses). Multicollinearity was not a concern (COVID-19 anxiety, $\mathrm{VIF}=1$, Tolerance $=1$ ). According to the findings, $19 \%$ of depression variance was explained by COVID-19 anxiety $(F=91.70 ; p<.0001)$ and COVID-19 anxiety emerged as a significant predictor of depression $(\beta=.43$; $p<.001$; Confidence Interval .46 -.70). Additionally, $2 \%$ of COVID-19-related panic shopping variance was explained by COVID-19 anxiety $(F=9.04 ; p<.003)$ and COVID-19 anxiety significantly predicted panic shopping $(\beta=.15 ; p<.003$; Confidence Interval .04 - .18).

Our third hypothesis was that participants who have recently experienced illness or know someone suspected of having COVID-19 will experience more significant COVID-19 anxiety. To test this hypothesis, we examined

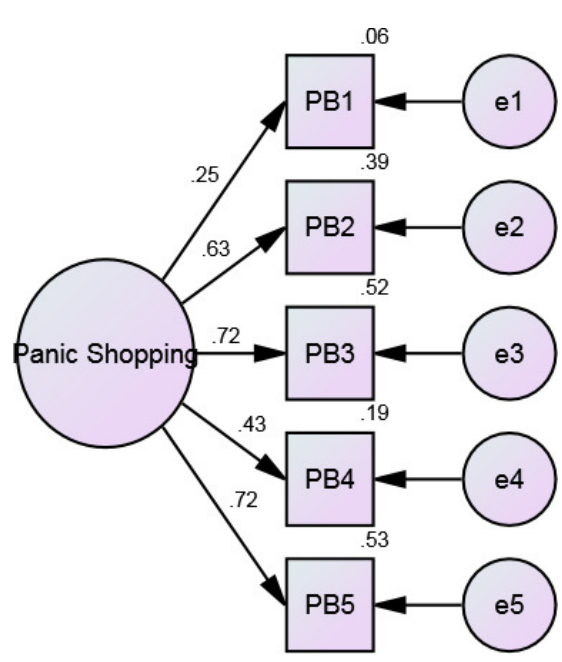

Figure 1. The one-factor model of the COVID-19-Related Panic Shopping Questionnaire

responses to two questions ("Do you personally know of anyone who was suspected of having been infected with COVID-19?" and “Did you get sick in the past year?”). A 2 $\times 2$ factorial ANOVA was used to investigate the main and interaction effects of knowing someone suspected of having been infected with COVID-19 and getting sick in the past year on COVID-19 anxiety.

As shown in Table 6, the main effect of getting sick past year was significant $(F=18.93 ; p<.0001)$. Based on the mean scores, individuals who got sick last year $(M=40.23)$ had higher levels of COVID-19 anxiety than those who did not $(M=37.72)$. Also, there was a significant main effect of knowing someone suspected of having been infected with 
COVID-19 ( $F=55.56 ; p<.0001)$. Individuals who knew someone suspected of having COVID-19 ( $M=41.06)$ reported higher COVID-19 anxiety than those who did not know someone suspected of having COVID-19 $(M=37.26)$. Additionally, the interaction effect of getting sick in the past year and knowing someone suspected of having COVID-19 was significant $(F=13.993 ; p<.0001)$. Those with the highest COVID-19 anxiety report having been sick in the past year and knowing someone with COVID-19 (Figure 2).

\section{DISCUSSION}

Research has shown that, in addition to severe physical health consequences, COVID-19 has posed a range of mental health consequences such as widespread stress, anxiety, and depression. ${ }^{1}$ Clarifying the predictors and consequences of COVID-19- related psychological problems can lead to successful therapeutic responses. Accordingly, the present study aimed to investigate psychological determinants and consequences of COVID-19 anxiety during the outbreak of COVID-19 in Iran. Per our hypotheses, we found that COVID-19 anxiety was associated with general health anxiety, uncertainty intolerance, interpersonal trust, depression, and panic shopping. COVID-19 anxiety was more significant among participants who had recently experienced personal illness or knew someone who had experienced illness. In addition, the present study served to establish the psychometric properties of a questionnaire used to assess panic shopping behavior.

General health anxiety, uncertainty intolerance, and interpersonal trust emerged as significant predictors of COVID-19 anxiety. Health anxiety has become increasingly common since the outbreak of COVID-19 and is associated with disease-related media coverage. ${ }^{7}$ Maladaptive illness cognition ${ }^{8}$ occurs in many individuals with health anxiety. Maladaptive cognitions may cause individuals to exhibit negative affect and rumination about their distress. ${ }^{9,11}$ Health anxiety may trigger a vicious cycle of obsessions and compulsions about COVID-19. ${ }^{7}$ Sufferers may overestimate the probability of having COVID-19, show excessive health information-seeking behavior, have COVID-19-related negative future imaginings, catastrophize ambiguous signs, amplify bodily symptoms, need reassurance, and exhibit excessive safety-seeking. ${ }^{6,7}$ Such maladaptive illness cognitions may fuel COVID-19 anxiety. Therefore, the assessment of general health anxiety is likely to be useful in identifying those most vulnerable to COVID-19 anxiety.

Our findings show that uncertainty intolerance predicts COVID-19 anxiety. This concurs with research showing that intolerance of uncertainty is a risk factor for general health anxiety. ${ }^{14,43-45}$ More specifically, our results suggest that prospective anxiety, in comparison to inhibitory anxiety, is more strongly correlated with COVID-19 anxiety. Prospective anxiety is anticipatory anxiety most implicated in nonphobic anxiety disorders, such as generalized anxiety disorder. ${ }^{46}$ Therefore, it seems that COVID-19 anxiety may be a kind of generalized worry relevant to broad threat-responding rather than to explicit threat cues. ${ }^{47}$ Our findings suggest that therapeutic approaches that are successful with generalized anxiety disorder are likely to be efficacious

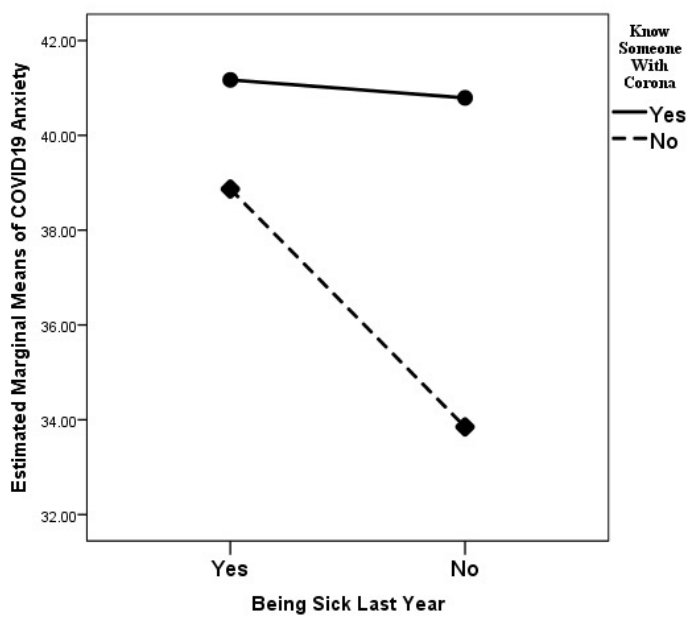

Figure 2. The interaction effect of getting sick in the past year and knowing someone who was suspected of being infected with COVID-19 on COVID-19 anxiety

when treating COVID-19 anxiety. In addition, government and health officials should strive to provide accurate information about the pandemic and reduce reliance on misinformation to maximize psychological certainty in the communities they serve.

It makes logical sense that interpersonal trust is related to COVID-19 anxiety since trust is essential for health at both the societal and individual levels. ${ }^{48}$ Individuals with low levels of trust do not trust health experts and politicians to protect them against the threat of disease. They may underestimate the ability (e.g., competence), benevolence (e.g., empathy), and integrity (e.g., honesty) of governments and health officials. Lower levels of interpersonal trust are associated with more significant COVID-19 anxiety, perhaps because low confidence makes people feel more vulnerable to contracting COVID-19. They are afraid of getting sick and not being able to access quality health care.

To some extent, government and health officials may engender increased trust in the healthcare system by providing consistent and accurate information. Nonetheless, individuals who show low interpersonal trust will tend to be more vulnerable to COVID-19-related anxiety. Low confidence and the associated anxiety may hinder efforts to curb the spread of the pandemic since trust may be necessary for widespread compliance with testing and vaccinations.

Our findings revealed that COVID-19 anxiety was a significant predictor of depression and panic shopping. This result concurs with previous findings of an association between health anxiety and depression. ${ }^{10}$ Depression has also been documented as a common mental health problem during pandemics. ${ }^{49}$ High levels of COVID-19 anxiety, combined with disruptions in work and social functions, may trigger depression. Our findings suggest that therapeutic approaches to COVID-19 anxiety should address depression since it will often occur comorbidly with anxiety.

Our results show that COVID-19 anxiety appears to be 
associated with false safety behaviors such as panic shopping. Safety behaviors are commonly observed under anxiety-provoking conditions and aim to relieve anxiety. Examples of commonly reported safety behaviors include ingesting a beta-blocker before a public presentation, carrying rescue medication, avoiding going out at night, and avoiding arguments. ${ }^{50}$ The compulsion to perform safety behaviors can have corrosive consequences for individuals and communities. While safety behaviors can relieve anxiety temporarily, these behaviors increase anxiety in the long run by avoiding stressful situations and confirming inaccurate threat alarms. Research confirms the pivotal role of safety behaviors in the maintenance of anxiety disorders ${ }^{50-52}$ and health anxiety. ${ }^{53,54}$ Safety behaviors, and more specifically panic shopping, play a prominent role in COVID-19 anxiety. In this regard, restorative strategies, negative reinforcement, and biased attentional processes ${ }^{51}$ can underlie detrimental effects of panic shopping on COVID-19 anxiety by elevating threat perception and health-related excessive and biased thoughts. While panic shopping may be fueled by COVID-19 anxiety, it may also maintain COVID-19 anxiety. The present findings highlight the potential importance of investigating panic shopping in the maintenance of COVID-19 anxiety.

According to illness cognition theory, ${ }^{8}$ expectations of vulnerability to illness affect physical and mental health. Knowing someone suspected of having COVID-19 and having been sick in the past year is illness-related information that can prime more significant COVID-19 anxiety. This illness-related information might elicit biased and excessive cognitive and behavioral responses, which can exacerbate COVID-19 anxiety. Our results suggest that individuals experiencing a personal illness or illness of a loved one should be assessed for anxiety when initially seeking treatment for the physical illness. This will allow for the early detection of potentially serious mental health problems.

We are not aware of any previous research on panic shopping during the COVID-19 pandemic. To measure unintended, immediate, and unreflective purchases regarding the COVID-19 outbreak, we constructed a 5-item scale adapted from previous impulse buying measures. ${ }^{36-38}$ According to the EFA, CFA, and internal reliability, the COVID-19-Related Panic Shopping Questionnaire had good psychometric properties and appeared to possess good practical utility. This questionnaire could provide a convenient method to evaluate impulsive buying tendencies re- lated to the COVID-19 pandemic. Due to the emergence of extreme shopping behaviors during the COVID-19 pandemic, this questionnaire appears well suited for research and clinical settings.

Several limitations of this study should be noted. The use of self-report data is one limitation. This study was conducted in Iran. Cultural differences may make it difficult to generalize findings to other regions or cultural groups. Using convenience sampling for recruiting the participants was another limitation. The measurements were not completely masked; therefore, social desirability may have influenced responses.

\section{IMPLICATIONS FOR PRACTICE AND/OR POLICY}

Despite some limitations, our results have potential clinical implications. Pandemics can develop rapidly. Health care systems need to be both medically and psychologically ready. Developing effective and individually tailored psychological support strategies will necessitate identifying people who are at high risk for severe psychological reactions. Assessment should include a comprehensive evaluation of risk factors (e.g., poor health status, high uncertainty intolerance, low interpersonal trust, knowing someone infected). Health care providers should also be sensitive to the potential adverse effects of increased depression and safety behaviors such as compulsive shopping.

\section{CONCLUSIONS}

Our study showed that COVID-19 anxiety is associated with individual and interpersonal factors. First, health anxiety around the COVID-19 pandemic appears to be widespread and has maladaptive consequences (e.g., depression and panic shopping). Second, some individuals are prone to COVID-19 anxiety, with health anxiety, intolerance of uncertainty, and interpersonal trust playing significant roles. Third, knowing someone who got COVID-19 and being sick in the past year can lead to more significant COVID-19 anxiety. Finally, the COVID-19-Related Panic Shopping Questionnaire is a useful measure to evaluate panic buying as a false safety behavior during the COVID-19 pandemic.

Submitted: June 10, 2021 EST, Accepted: June 11, 2021 EST 


\section{REFERENCES}

1. Salari N, Hosseinian-Far A, Jalali R, et al. Prevalence of stress, anxiety, depression among the general population during the COVID-19 pandemic: A systematic review and meta-analysis. Global Health. 2020;16(1):57. doi:10.1186/s12992-020-00589-w

2. Xiang YT, Yang Y, Li W, et al. Timely mental health care for the 2019 novel coronavirus outbreak is urgently needed. The Lancet Psychiatry. 2020;7(3):228-229. doi:10.1016/s2215-0366(20)3004 6-8

3. Cao W, Fang Z, Hou G, et al. The psychological impact of the COVID-19 epidemic on college students in China. Psychiatry Research. 2020;287:112934. doi:1 0.1016/i.psychres.2020.112934

4. Wang C, Pan R, Wan X, et al. Immediate psychological responses and associated factors during the initial stage of the 2019 coronavirus disease (COVID-19) epidemic among the general population in China. IJERPH. 2020;17(5):1729. doi:10.3390/ijerph 17051729

5. Li S, Wang Y, Xue J, Zhao N, Zhu T. The impact of COVID-19 Epidemic Declaration on psychological consequences: A study on active Weibo users. IJERPH. 2020;17(6):2032. doi:10.3390/ijerph17062032

6. Taylor S, Asmundson GJG. Understanding and Treating Health Anxiety: A Cognitive-Behavioral Approach. Guilford; 2004. doi:10.1016/s1077-7229(0 4)80015-4

7. Asmundson GJG, Taylor S. How health anxiety influences responses to viral outbreaks like COVID-19: What all decision-makers, health authorities, and health care professionals need to know. Journal of Anxiety Disorders. 2020;71:102211. d oi:10.1016/j.janxdis.2020.102211

8. Leventhal H, Diefenbach M, Leventhal EA. Illness cognition: Using common sense to understand treatment adherence and affect cognition interactions. Cogn Ther Res. 1992;16(2):143-163. do $\underline{\mathrm{i}: 10.1007 / \mathrm{bf} 01173486}$

9. Marcus DK, Hughes KT, Arnau RC. Health anxiety, rumination, and negative affect: A mediational analysis. Journal of Psychosomatic Research. 2008;64(5):495-501. doi:10.1016/i.jpsychores.2008.0 $\underline{2.004}$
10. Noyes R Jr, Kathol RG, Fisher MM, Phillips BM, Suelzer MT, Woodman CL. Psychiatric comorbidity among patients with hypochondriasis. General Hospital Psychiatry. 1994;16(2):78-87. doi:10.1016/016 $\underline{\text { 3-8343(94)90049-3 }}$

11. Wolfradt U, Oemler M, Braun K, Klement A. Health anxiety and habitual rumination: The mediating effect of serenity. Personality and Individual Differences. 2014;71(December 2014):130-134. doi:1 0.1016/j.paid.2014.07.030

12. Dugas MJ, Gagnon F, Ladouceur R, Freeston MH. Generalized anxiety disorder: A preliminary test of a conceptual model. Behaviour Research and Therapy. 1998;36(2):215-226. doi:10.1016/s0005-7967(97)0007 $\underline{0-3}$

13. Zandifar A, Badrfam R. Iranian mental health during the COVID-19 epidemic. Asian Journal of Psychiatry. 2020;51:101990. doi:10.1016/i.ajp.2020.10 $\underline{1990}$

14. Fergus TA, Bardeen JR. Anxiety sensitivity and intolerance of uncertainty: Evidence of incremental specificity in relation to health anxiety. Personality and Individual Differences. 2013;55(6):640-644. doi:1 0.1016/j.paid.2013.05.016

15. Carleton RN, Norton PJ, Asmundson GJG. Fearing the unknown: A short version of the Intolerance of Uncertainty Scale. Journal of Anxiety Disorders. 2007;21(1):105-117. doi:10.1016/j.janxdis.2006.03.01 $\underline{4}$

16. Taylor C. Here's why people are panic buying and stockpiling toilet paper to cope with coronavirus fears. CNBC. Published online March 11, 2020. http s://www.cnbc.com/2020/03/11/heres-why-people-ar e-panic-buying-and-stockpiling-toilet-paper.html

17. Rotter JB. A new scale for the measurement of interpersonal trust1. J Personality. 1967;35(4):651-665. doi:10.1111/j.1467-6494.1967.tb $\underline{01454 . x}$

18. Schneider IK, Konijn EA, Righetti F, Rusbult CE. A healthy dose of trust: The relationship between interpersonal trust and health. Personal Relationships. 2011;18(4):668-676. doi:10.1111/j.1475-6811.2010.01 $\underline{338 . x}$

19. Fabrigar LR, Wegener DT, MacCallum RC, Strahan EJ. Evaluating the use of exploratory factor analysis in psychological research. Psychological Methods. 1999;4(3):272-299. doi:10.1037/1082-989x.4.3.272 
20. Comrey AL, Lee HB. A First Course in Factor

Analysis. Lawrence Eribaum Associates; 1992.

21. Wheaton MG, Abramowitz JS, Berman NC, Fabricant LE, Olatunji BO. Psychological predictors of anxiety in response to the H1N1 (swine flu) pandemic. Cogn Ther Res. 2012;36(3):210-218. doi:1 0.1007/s10608-011-9353-3

22. Shabahang R, Aruguete M, McCutcheon L. Online health information utilization and online news exposure as predictor of COVID-19 anxiety. North American Journal of Psychology. 2020;22(3):469-482.

23. Shabahang R, Aruguete MS, McCutcheon L. Video-based cognitive-behavioral intervention for COVID-19 anxiety: A randomized controlled trial. Trends Psychiatry Psychother. Published online 2020. $\underline{\mathrm{d}}$ oi:10.47626/2237-6089-2020-0056

24. Nourisaeid A, Shabahang R, Bagheri

Sheykhangafshe F, Saeedi M, Mousavi M. Comparison of online health information utilization, online shared identity, and online shared information usage in different levels of COVID-19 anxiety. Journal of Research in Psychological Health. 2020;14(1):28-39.

25. Salkovskis PM, Rimes KA, Warwick HMC, Clark DM. The Health Anxiety Inventory: Development and validation of scales for the measurement of health anxiety and hypochondriasis. Psychol Med. 2002;32(5):843-853. doi:10.1017/s0033291702005822

26. Abramowitz JS, Deacon BJ, Valentiner DP. The Short Health Anxiety Inventory: Psychometric properties and construct validity in a non-clinical sample. Cogn Ther Res. 2007;31(6):871-883. doi:10.10 07/s10608-006-9058-1

27. Alberts NM, Hadjistavropoulos HD, Jones SL, Sharpe D. The Short Health Anxiety Inventory: A systematic review and meta-analysis. Journal of Anxiety Disorders. 2013;27(1):68-78. doi:10.1016/j.jan $\underline{\text { xdis.2012.10.009 }}$

28. Freeston MH, Rhéaume J, Letarte H, Dugas MJ, Ladouceur R. Why do people worry? Personality and Individual Differences. 1994;17(6):791-802. doi:10.101 6/0191-8869(94)90048-5

29. Khawaja NG, Yu LNH. A comparison of the 27-item and 12-item intolerance of uncertainty scales. Clinical Psychologist. 2010;14(3):97-106. doi:1 0.1080/13284207.2010.502542

30. Chun KT, Campbell JB. The dimensionality of the Rotter Interpersonal Trust Scale. Psychol Rep. 1974;35(3):1059-1070. doi:10.2466/pr0.1974.35.3.105 $\underline{9}$
31. Beck AT, Steer RA, Carbin MG. Psychometric properties of the Beck Depression Inventory: Twentyfive years of evaluation. Clinical Psychology Review. 1988;8(1):77-100. doi:10.1016/0272-7358(88)90050-5

32. Beck AT, Steer RA, Brown GK. Manual for the Beck Depression Inventory-II. Psychological Corporation; 1996.

33. Dere J, Watters CA, Yu SCM, Bagby RM, Ryder AG, Harkness KL. Cross-cultural examination of measurement invariance of the Beck Depression Inventory-II. Psychological Assessment. 2015;27(1):68-81. doi:10.1037/pas0000026

34. Erford BT, Johnson E, Bardoshi G. Meta-Analysis of the English Version of the Beck Depression Inventory-Second Edition. Measurement and Evaluation in Counseling and Development. 2016;49(1):3-33. doi:10.1177/0748175615596783

35. Wang YP, Gorenstein C. Psychometric properties of the Beck Depression Inventory-II: A comprehensive review. Rev Bras Psiquiatr. 2013;35(4):416-431. doi:10.1590/1516-4446-2012-10 $\underline{48}$

36. Rook DW. The buying impulse. J Consum Res. 1987;14(2):189-199. doi:10.1086/209105

37. Badgaiyan AJ, Verma A, Dixit S. Impulsive buying tendency: Measuring important relationships with a new perspective and an indigenous scale. IIMB Management Review. 2016;28(4):186-199. doi:10.101 6/i.iimb.2016.08.009

38. Verplanken B, Herabadi AG. Individual differences in impulse buying tendency: Feeling and no thinking. Eur J Pers. 2001;15(S1):S71-S83. doi:10.1002/per.423

39. Nunnally JC, Bernstein IH. Psychometric Theory. McGraw-Hill; 1994.

40. Mueller RO. Basic Principles of Structural Equation Modeling: An Introduction to LISREL and EQS. Springer Science \& Business Media; 1999.

41. Kline RB. Principles and Practice of Structural Equation Modeling. 5th ed. The Guilford Press; 2011:3-427.

42. Hair JF Jr, Black WC, Babin BJ, Anderson RE. Multivariate Data Analysis: A Global Perspective. 7th ed. Pearson Education; 2010.

43. Abramowitz JS, Braddock AE. Psychological Treatment of Health Anxiety and Hypochondriasis: A Biopsychosocial Approach. Hogrefe; 2008. 
44. Fetzner MG, Asmundson GJG, Carey C, et al. How do elements of a reduced capacity to withstand uncertainty relate to the severity of health anxiety? Cognitive Behaviour Therapy. 2014;43(3):262-274. do i:10.1080/16506073.2014.929170

45. Wright KD, Lebell MANA, Carleton RN. Intolerance of uncertainty, anxiety sensitivity, health anxiety, and anxiety disorder symptoms in youth. Journal of Anxiety Disorders. 2016;41(June 2016):35-42. doi:10.1016/j.janxdis.2016.04.011

46. Hong RY, Lee SSM. Further clarifying prospective and inhibitory intolerance of uncertainty: Factorial and construct validity of test scores from the Intolerance of Uncertainty Scale. Psychological Assessment. 2015;27(2):605-620. doi:10.1037/pas0000 $\underline{074}$

47. Craske MG, Waters AM. Panic disorder, phobias, and generalized anxiety disorder. Annu Rev Clin Psychol. 2005;1(1):197-225. doi:10.1146/annurev.clin psy.1.102803.143857

48. Feng Z, Vlachantoni A, Liu X, Jones K. Social trust, interpersonal trust and self-rated health in China: A multi-level study. Int J Equity Health. 2016;15(1):180. doi:10.1186/s12939-016-0469-7

49. Douglas PK, Douglas DB, Harrigan DC, Douglas KM. Preparing for pandemic influenza and its aftermath: Mental health issues considered. International journal of emergency mental health. 2009;11(3):137-144.
50. Telch MJ, Lancaster CL. Is there room for safety behaviors in exposure therapy for anxiety disorders? In: Neudeck P, Wittchen HU, eds. Exposure Therapy: Rethinking the Mode-Refining the Method. Springer; 2012:313-334. https://doi.org/10.1007/978-1-4614-33 42-2_18

51. Helbig-Lang S, Petermann F. Tolerate or eliminate? A systematic review on the effects of safety behavior across anxiety disorders. Clinical Psychology: Science and Practice. 2010;17(3):218-233. doi:10.1111/j.1468-2850.2010.01213.x

52. Okajima I, Kanai Y, Chen J, Sakano Y. Effects of safety behaviour on the maintenance of anxiety and negative belief social anxiety disorder. Int J Soc Psychiatry. 2009;55(1):71-81. doi:10.1177/0020764008 $\underline{092191}$

53. Abramowitz JS, Moore EL. An experimental analysis of hypochondriasis. Behaviour Research and Therapy. 2007;45(3):413-424. doi:10.1016/j.brat.200 $\underline{6.04 .005}$

54. Olatunji BO, Etzel EN, Tomarken AJ, Ciesielski BG, Deacon B. The effects of safety behaviors on health anxiety: An experimental investigation. Behaviour Research and Therapy. 2011;49(11):719-728. doi:10.10 16/j.brat.2011.07.008 